\title{
Evaluation of Changes in Biochemical and Haematological Parameters of Albino Rats Following Subacute Oral Administration of Cinnamomum cassia (Cinnamon) Extract
}

\author{
C. N. Okwuosa ${ }^{1}$, N. C. Azubuike ${ }^{1}$ and C. P. Okorie ${ }^{2^{*}}$ \\ ${ }^{1}$ Department of Medical Laboratory Sciences, Faculty of Health Sciences and Technology, College of \\ Medicine, University of Nigeria, Enugu Campus, Nigeria. \\ ${ }^{2}$ Department of Medical Biochemistry, Faculty of Basic Medical Sciences, College of Medicine, \\ University of Nigeria, Enugu Campus, Nigeria.
}

\begin{abstract}
Authors' contributions
This work was carried out in collaboration among all authors. Author CNO conceptualized the study, designed the protocol, performed the investigations in the study, critically reviewed the literature, and wrote the first draft of the manuscript. Author CPO managed the literature searches and wrote part of the final manuscript. Author NCA collected data, performed the statistical analysis, proof-read the first manuscript draft, and wrote part of the final manuscript. All authors read and approved the final manuscript.

Article Information

DOI: $10.9734 / A R R B / 2021 / v 36 i 630393$ Editor(s):

(1) Dr. Paola Angelini, University of Perugia, Italy. Reviewers:

(1) R. Nambu Mahalakshmi, Raja College of Arts And Science, India (2) Ernesto Cornelio Terán Portelles, Universidad de La Habana, Cuba. Complete Peer review History: http://www.sdiarticle4.com/review-history/70473
\end{abstract}

Original Research Article

Received 24 April 2021

Accepted 29 June 2021

Published 09 July 2021

\section{ABSTRACT}

Background: Cinnamomum cassia stem bark is used traditionally for the treatment of digestive disorders, diabetes and to alleviate symptoms of cold or flu.

Aim: The present study evaluated biochemical and haematological changes in male albino rats after exposure to the stem bark ethanolic extract of Cinnamomum cassia (SBECC).

Study Design: An experimental study which lasted for 19 days.

Place and Duration of Study: Department of Medical Laboratory Sciences and Animal House, College of Medicine, University of Nigeria, Enugu Campus, between April 2019 and August 2019. 
Methodology: Twenty (20) rats weighing 130-170 g were used. Graded doses (100, 200 and $400 \mathrm{mg} / \mathrm{kg}$ body weight) of the SBECC were orally administered to the animals in groups B, C and D respectively, once daily for 18 days. Group A served as the normal control and received only the vehicle $(5 \mathrm{ml} / \mathrm{kg}$ of $0.25 \mathrm{~N}$ sodium carbonate). On Day 19 , body weights of the rats were measured and blood samples obtained via retro-orbital puncture, were placed into plain tubes and tripotassium ethylene diamine tetra-acetic acid ( $\left.K_{3} E D T A\right)$ containers for biochemical and haematological studies respectively.

Results: Weight gain was observed in all treatment groups and control. The highest and lowest percentage weight gain was observed in Group C (51\%) and Group B (33\%) respectively. All the doses of the extract significantly decreased serum cholesterol levels when compared to the control $(P<0.05)$. Treatment with $400 \mathrm{mg} / \mathrm{kg}$ SBECC (Group D) significantly increased serum Alkaline phosphatase $(224.00 \pm 12.88 \mathrm{iu} / \mathrm{l})$ and creatinine levels $(85.60 \pm 7.40)$ when compared to the control $(140.00 \pm 26.47$ and $63.60 \pm 7.60$ respectively) $(P<0.05)$, whereas treatment with $200 \mathrm{mg} / \mathrm{kg}$ SBECC significantly increased urea and creatinine levels $(P<0.05)$. No significant changes were observed in the haematological parameters of the treated rats compared to the control.

Conclusion: Sub-acute oral administration of Cinnamomum cassia stem bark extract at doses lower than $500 \mathrm{mg} / \mathrm{kg}$ may not exert toxic effects on haematological parameters but can alter some serum biochemical parameters in rats.

Keywords: Cinnamomum cassia; sub-acute studies; toxicology; biochemical and haematological parameters.

\section{INTRODUCTION}

Since antiquity, even before the synthetic pharmaceutical drugs were introduced, plants have been used for medicinal purposes and their products are becoming popular as alternative medicines worldwide. Over the years, there has been a growing academic and industrial involvement in traditional medicine. Plants provide a readily available, cheap and less toxic source of drug development. Researchers are carrying out detailed scientific investigations to provide evidences for the efficacy, safety and toxicity of herbal medicines as well as their mechanisms of action. Even though plants are generally regarded to be safe, there are plant materials which are hazardous to human beings, thus, showing the need for toxicity studies prior to human consumption.

Cinnamomum cassia, commonly known as cinnamon and belonging to the family Lauraceae, is an evergreen tall tree widely cultivated in Asia and some parts of Africa. The stem bark is the outer skin of the stem which bears the organic material, cinnamon, often extracted for its medicinal use and in spicing up foods. It contains several active components such as essential oils (cinnamic acid, cinnamaldehyde and cinnamate), tannin, and carbohydrates [1,2]. These have various pharmacological activities including antioxidant, anti-microbial, anti-inflammatory, chemopreventive, anti-diabetic, hypolipidemic and anti-cancer activities [3-9]. The mixture of cinnamon with fresh ginger in a tea, has been used to alleviate symptoms of cold or flu in some energy-based medical systems such as Traditional Chinese Medicine [10]. The stem bark is conventionally used as a condiment and flavoring substance and more so as an aide for the treatment of digestive disorders and diabetes. However, there is currently insufficient data and conflicting reports regarding the toxicity profile of the plant material. The present study, therefore, was aimed at investigating the subacute toxicity profile of the stem bark extract of Cinnamomum cassia on some biochemical and haematological parameters in male albino rats.

\section{MATERIALS AND METHODS}

\subsection{Procurement and Reconstitution of Plant Material}

Fine powder of Cinnamomum cassia stem bark ethanolic extract was procured from Sundown benefits $^{\circledR}$ (Sundown Inc., Booa Ratton, Florida, USA). $10 \mathrm{~g}$ of the fine powder of $C$. cassia stem bark was weighed and reconstituted with $0.25 \mathrm{~N}$ sodium carbonate $\left(\mathrm{Na}_{2} \mathrm{CO}_{3}\right)$ which served as the Vehicle, and made up to $100 \mathrm{ml}$ with the same solvent to a final concentration of $100 \mathrm{mg} / \mathrm{ml}$. This was stored at $4{ }^{\circ} \mathrm{C}$ in a refrigerator throughout the period of administration. 


\subsection{Laboratory Animals}

A total of twenty (20) apparently healthy male albino Wistar rats weighing $130-170 \mathrm{~g}$ were used for the study. They were obtained from the Faculty of Veterinary Medicine, University of Nigeria, Nsukka and housed at the Animal House of the College of Medicine, Enugu Campus, University of Nigeria. To prevent coprophagy, the animals were kept in clean wire-mesh cages which had openings beneath for exit of rats' faeces. They were weighed and grouped into four (A-D) of 5 rats per group according to their weights. Before the commencement of the study, the animals were allowed to acclimatize for two weeks. Animal housing was maintained under controlled environmental conditions of light (12 h light/dark cycle) and temperature $\left(25 \pm 2^{\circ} \mathrm{C}\right)$. They were fed ad libitum with commercial rat feed (Top Feeds ${ }^{\circledR}$ limited, Ibadan, Nigeria) and clean water. All the animal experiments were performed in conformity with institutional protocols and the guidelines for care and use of animals for scientific research [11].

\subsection{Experimental Design and Conduct}

Graded doses of 100,200 and $400 \mathrm{mg} / \mathrm{kg}$ body weight of the plant extract were orally administered to all rats in test groups $B, C$ and $D$ respectively, once daily for 18 days. Group $A$ served as the control and received only the vehicle $(5 \mathrm{ml} / \mathrm{kg}$ body weight of $0.25 \mathrm{~N}$ sodium carbonate). At the end of the treatment period, blood samples were obtained from each rat by retro-orbital puncture into an anticoagulated (EDTA-K3) bottle (for analysis of haematological parameters) and into a plain tube for the estimation of some biochemical parameters.

\subsubsection{Haematological analysis}

The haematological parameters were analyzed within $24 \mathrm{hrs}$ of sample collection by manual haematological methods using standard operating procedure as described by Dacie et al., [12].

\subsubsection{Biochemical assay}

The sera for the biochemical assays were separated from the whole blood at room temperature and stored frozen prior to analysis. Alanine and Aspartate transaminases were analyzed as described by Reitman et al., [13], Alkaline phosphatase as described by Kind et al.,
[14], blood urea by Diacetyl Monoxime method as described by Natelson et al., [15] and serum creatinine by Jaffe's reaction as described by Fabing et al., [16], whereas the total cholesterol was by enzymatic method following the $\mathrm{QCA}^{\circledR}$ manufacturer's guideline.

\subsubsection{Body weight measurement}

The body weights before (Pre-administration) and after (Post-administration) treatments for each rat from the control and treatment groups were measured and recorded. Body weight changes expressed in percentage were computed as follows:

BWC $(\%)=(B W A-B W B) / B W B \times 100$

(Where BWC: Body weight change; BWA: Body weight after treatments; BWB: Body weight before treatments).

\subsection{Statistical Analysis}

All numerical data obtained from the present study were statistical analyzed using Statistical package for Social Sciences (SPSS) data analytical software (version 23.0) [Chicago, IL, USA]. The mean pre-administration and postadministration body weights of the rats in all groups were represented as bar charts while the body weight changes were expressed as percentages. Differences between means of biochemical and haematological parameters were determined using analysis of variance (ANOVA), Students " $t$ " test and Tukey post hoc test for multiple comparisons. Data were expressed as mean \pm standard error of mean [SEM] and presented in tabular formats. $P$ less than 0.05 was considered statistically significant.

\section{RESULTS}

\subsection{Effect of Oral Administration of SBECC on Some Haematological Parameters}

The effect of oral subacute administration of the stem bark extract of $C$. cassia (SBECC) on some haematological parameters is shown in Table 1. Assessment of all the parameters at the end of the treatments revealed significant difference when compared with the control $(P>0.05)$. 
Table 1. Sub-acute effect of Cinnamonium cassia on some haematological parameters in male albino wistar rats

\begin{tabular}{|c|c|c|c|c|c|}
\hline Treatments & WBC Total (x10 $/ \mathrm{L})$ & Platelet Counts (x109/L) & Packed Cell Volume (\%) & Neutrophils (\%) & Lymphocytes (\%) \\
\hline Vehicle (Control) & $10.84 \pm 1.80$ & $110.00 \pm 33.47$ & $38.40 \pm 2.22$ & $33.80 \pm 11.59$ & $66.20 \pm 11.59$ \\
\hline $100 \mathrm{mg} / \mathrm{kg}$ SBECC & $7.06 \pm 1.18$ & $110.00 \pm 21.21$ & $44.20 \pm 1.02$ & $43.60 \pm 2.14$ & $56.40 \pm 2.14$ \\
\hline $200 \mathrm{mg} / \mathrm{kg}$ SBECC & $7.38 \pm 0.61$ & $162.00 \pm 3.74$ & $42.40 \pm 0.98$ & $38.00 \pm 3.33$ & $62.00 \pm 3.33$ \\
\hline $400 \mathrm{mg} / \mathrm{kg}$ SBECC & $11.26 \pm 2.10$ & $180.00 \pm 32.29$ & $39.20 \pm 1.32$ & $45.60 \pm 5.98$ & $54.40 \pm 5.97$ \\
\hline
\end{tabular}

Data expressed as mean \pm SEM; $n=5$. Level of statistical significance is set at $P<0.05$ when compared to the control group. $S B E C C=$ Stem Bark Extract of Cinnamomum cassia

Table 2. Effect of sub-acute administration of Cinnamonium cassia on some biochemical parameters in male albino wistar rats

\begin{tabular}{|c|c|c|c|c|c|c|}
\hline Treatments & ALT(iu/L) & AST(iu/L) & ALP(iu/L) & Blood Urea (mmol/L) & Serum Creatinine $(\mu \mathrm{mol} / \mathrm{L})$ & $\begin{array}{l}\text { Serum Cholesterol } \\
(\mathrm{mmol} / \mathrm{L})\end{array}$ \\
\hline Vehicle (Control) & $24.60 \pm 3.76$ & $40.20 \pm 2.24$ & $140.00 \pm 26.47$ & $3.82 \pm 0.22$ & $63.60 \pm 7.60$ & $2.66 \pm 0.07$ \\
\hline $100 \mathrm{mg} / \mathrm{kg}$ SBECC & $23.00 \pm 2.28$ & $50.60 \pm 6.73$ & $161.20 \pm 18.49$ & $4.48 \pm 0.22$ & $59.80 \pm 7.11$ & $2.34 \pm 0.04^{*}$ \\
\hline $200 \mathrm{mg} / \mathrm{kg}$ SBECC & $19.00 \pm 2.00$ & $39.40 \pm 0.40$ & $126.60 \pm 9.81$ & $4.70 \pm 0.00^{*}$ & $85.80 \pm 4.40^{*}$ & $2.34 \pm 0.04^{*}$ \\
\hline $400 \mathrm{mg} / \mathrm{kg}$ SBECC & $35.00 \pm 3.52$ & $44.20 \pm 1.20$ & $224.00 \pm 12.88^{*}$ & $4.26 \pm 0.27$ & $85.60 \pm 7.40^{*}$ & $2.30 \pm 0.00^{*}$ \\
\hline
\end{tabular}

Data expressed as mean \pm SEM; $n=5$. Level of statistical significance is set at $P<0.05$ and * denotes statistically significant difference when compared to the control group. Keys: $\quad A L T=$ Alanine transaminase; $A S T=$ Aspartate transaminase; ALP=Alkaline Phosphatase; SBECC=Stem Bark Extract of Cinnamomum cassia 


\subsection{Effect of Oral Administration of SBECC on Some Serum Biochemical Parameters}

Table 2 shows the effect of oral subacute administration of SBECC on the mean serum levels of some biochemical parameters. There was no statistically significant difference in the mean serum levels of ALT and AST in all SBECC-treated groups when compared with the control $(P>0.05)$. More so, no significant difference was observed in serum ALP levels in groups $B$ and $C(100 \mathrm{mg} / \mathrm{kg}$ and $200 \mathrm{mg} / \mathrm{kg}$ body weight SBECC respectively) $(P>0.05)$, however, a significantly higher ALP level (224.00 $\pm 12.88 \mathrm{iu} / \mathrm{l})$ was observed in Group D (400mg/kg body weight SBECC) when compared to control (Vehicle-treated) group $(P=0.07)$.

Furthermore, the extract caused an increase in serum urea levels but the only statistically significant increase was found in group C (200mg/kg body weight SBECC) when compared to the control $(P=0.02)$. Creatinine levels were also significantly increased in groups $C$ (200mg/kg body weight SBECC; $P=0.04$ ) and D $(400 \mathrm{mg} / \mathrm{kg}$ body weight SBECC; $\mathrm{P}=0.07)$. Conversely, SBECC significantly reduced mean cholesterol levels of all the treated rats (groups $B, C$ and D) when compared with the control $(P<$ 0.01).

\subsection{Body Weight Changes of Animals}

Fig. 1 shows the bar chart representing the mean body weights of rats before (Pre-administration) and after (Post-administration) oral gavage treatment with SBECC for 18 days. All the rats in the control and treatment groups gained weight by the end of the experiment. The percentage weight gain in the control group was $40 \%$. Lower percentage weight gains were observed in Groups B (33\%) and D (35\%), however the highest percentage weight gain was observed in Group C (51\%).

\section{DISCUSSION}

The present study was conducted to evaluate the biochemical and toxicological effects of stem bark extract of Cinnamomum cassia (SBECC) in male albino rats by their effects on liver enzymes, kidney function and some haematological parameters. The determination of the toxicity profile of plant materials has become a pertinent step in the discovery of therapeutic agents.

Alanine transaminase (ALT) and aspartate transaminase (AST) are the key enzymes known to be associated with liver parenchymal cells and when there is hepatic injury, the enzymes leak into the blood stream from where they are measured. The greater the degree of the liver damage, the higher the activities of both enzymes [17]. However, ALT is well-known to be the most liver-specific enzyme and thus a better marker for detecting liver damage. Since both ALT and AST were not significantly altered in the present study, it thus suggests that the extract is not toxic to the hepatocytes. Previous studies in humans and experimental animals have documented a similar finding [18-20], whereas others have reported a decreasing effect on the enzymes following treatment [21]. This decreasing effect has also been reported by some researchers who evaluated the hepatoprotective effect of cinnamon in rats $[22,23]$. In both studies, the extract was observed to reduce the elevated levels of the enzymes (ALT and AST) caused by the agents used for liver injury induction in the animal models. The authors attributed this hepatoprotective effect to the antioxidant properties of the extract, having been able to quench reactive oxygen species and stimulate cellular antioxidant system.

Alkaline phosphatase (ALP), on the other hand, was significantly increased in the highest dose treatment group $(400 \mathrm{mg} / \mathrm{kg}$ body weight) unlike the lower doses which left the ALP levels unaltered. The enzyme is primarily found in the liver and bones although small amounts are produced by epithelial cell lining of kidneys, intestines and placenta [24]. The hepatic form of the ALP is mostly found in sinusoidal membranes and at the epithelial cell lining of the bile canaliculi [25]. A rise in serum ALP levels is observed physiologically during bone growth and pathologically in bone disease [26]. More so, increased ALP levels have been reported in intestinal inflammatory conditions in rats, and it has been documented that these rodents have higher intestinal ALP levels than the hepatic form [27]. Perhaps the significant increase in ALP in the current study, may be due to an effect of the extract on either the liver, bone and/or intestines. This finding should be further investigated so as to determine the source of the elevated levels of ALP. 


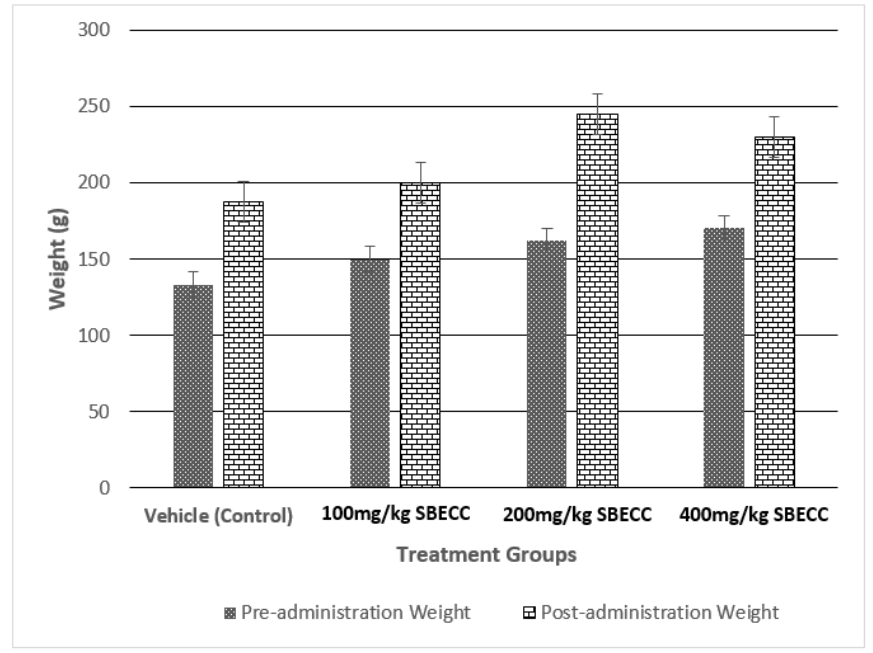

Fig. 1. Bar chart showing pre- and post-administration body weight changes of the animals following an 18-day oral treatment with $C$. cassia extract

Each bar represents Mean \pm S.E.M for each group of rats $(n=5)$

Blood urea and creatinine are indicators of renal function [28]. The kidneys are the target organs of toxic exogenous compounds since the organ is involved in drug elimination in the body system. In the present study, the marked increase observed in renal function parameters suggests that the kidney may not be able to excrete these products efficiently. The rate of glomerular filtration is reduced in renal diseases thereby leading to urea and creatinine retention [29]. Since urea and creatinine are biomarkers for kidney dysfunction, this result is suggestive of deranged renal function, which is contrary to the work of Chaudhary et al., [30] which documented that Cinnamon bark extract reduced both serum urea and creatinine in diabetic mice. Perhaps, the renotoxic potential of the extract as observed in the current study, should be further investigated by histopathological evaluation of renal tissues of animal models following treatment with the extract.

In the current study, the statistically significant decrease in total serum cholesterol levels is in line with the work of Khan et al., [31] which documented a cholesterol lowering effect of cinnamon on people with type 2 diabetes. In their study, a time-dependent decrease in serum cholesterol levels was noted in all three groups consuming cinnamon and no change was observed in the placebo groups. Another study in humans documented a similar decrease in individuals with elevated serum glucose [32] whereas a study on broiler chicks showed no change on serum cholesterol levels [20]. Yun et al [33], conversely, documented statistically elevated levels of total cholesterol after a 13week repeat-dose-oral toxicity study while treating rats with doses of cinnamon up to $2000 \mathrm{mg} / \mathrm{kg}$ body weight. These findings may suggest some controversy on the effect of cinnamon on blood lipids. It may be explained that this contrasting report could be dependent on the doses of the extract administered and duration of treatment, as the study of Yun et al. [33] involved the use of higher doses over a long period of treatment, whereas the doses used in the present study were lower and administered for a shorter period. The inference may be that higher doses of cinnamon have a potential of elevating total cholesterol levels whereas lower doses of below $500 \mathrm{mg} / \mathrm{kg}$ body weight may exert cholesterol lowering effects. Recent studies have also demonstrated and further support this cholesterol lowering property in both normal and hypercholesterolemic rats [34,35].

The relevance of evaluating blood parameters in the present study is due to the sensitivity of the blood system to toxic compounds. The blood stream is the main transport medium for xenobiotics and drugs [36]. The findings of the haematological assay in this study suggest that cinnamon extract is non-haematotoxic, since no significant difference was observed in all groups receiving the extract when compared to the control. This observation is supported by a previous work [37] which documented a similar non-significant effect on the differential white cell counts of rats after a 7-day and 14-day oral 
treatment with 100,500 and $2000 \mathrm{mg} / \mathrm{kg}$ body weight of cinnamon extract, and with the dose of $2 \mathrm{~g} / \mathrm{kg}$ body weight producing no lethality in the acute toxicity testing. As documented by the researchers, the duration of their subacute toxicity studies is similar to that conducted in the present study. Thus, it may be further inferred that the administration of $C$. cassia extract on subacute basis, may not exert any deleterious effect on haematological parameters.

\section{CONCLUSION}

The stem bark extract of Cinnamomum cassia produced no toxic effect on the haematological parameters and some liver marker enzymes after an oral sub-acute treatment. However, an increased Alkaline phosphatase (ALP) level was observed with the highest dose treatment in this study, which calls for caution in prolonged use, especially for people with liver and bone diseases. The lowering effect of the extract on total serum cholesterol levels may be further explored for its beneficial use in the treatment of cardiovascular diseases in humans. Further research is recommended to isolate the bioactive principle responsible for this effect as well as establish its mode of action.

\section{DISCLAIMER}

The products used for this research are commonly and predominantly used products in our area of research and country. There is absolutely no conflict of interest between the authors and producers of the products because we do not intend to use these products as an avenue for any litigation but for the advancement of knowledge. Also, the research was not funded by the producing company rather it was funded by personal efforts of the authors.

\section{ETHICAL APPROVAL}

All authors hereby declare that "Principles of laboratory animal care" (NIH publication No. 8523, revised 1985) were followed, as well as specific national laws where applicable. All experiments have been examined and approved by the appropriate Institutional ethics committee.

\section{COMPETING INTERESTS}

Authors have declared that no competing interests exist.

\section{REFERENCES}

1. Tanaka T. Chemical studies on plant polyphenols and formation of black tea polyphenols. Yakugaku Zasshi. 2008;128(8):1119-1131.

Available:https://doi.org/10.1248/yakushi.1 28.1119

2. Wijesekera RO. Historical overview of the cinnamon industry. CRC critical reviews in food science and nutrition. 1978;10(1):130.

Available:https://doi.org/10.1080/10408397 809527243

3. Kačániová $M$, Galovičová L, Valková V, Tvrdá E, Terentjeva M, Žiarovská J, Kunová S, Savitskaya T, Grinshpan D, Štefániková J, Felsöciová S. Antimicrobial and antioxidant activities of Cinnamomum cassia essential oil and its application in food preservation. Open Chemistry. 2021;19(1):214-227.

Available:https://doi.org/10.1515/chem2021-0191

4. Gunawardena D, Karunaweera N, Lee S, van Der Kooy F, Harman DG, Raju R, Bennett L, Gyengesi E, Sucher NJ, Münch G. Anti-inflammatory activity of cinnamon (C. zeylanicum and C. cassia) extractsidentification of E-cinnamaldehyde and omethoxy cinnamaldehyde as the most potent bioactive compounds. Food and function. 2015;6(3):910-919.

Available:https://doi.org/10.1039/C4FO006 80A

5. Schink A, Naumoska K, Kitanovski Z, Kampf CJ, Fröhlich-Nowoisky J, Thines E, Pöschl U, Schuppan D, Lucas K. Antiinflammatory effects of cinnamon extract and identification of active compounds influencing the TLR2 and TLR4 signaling pathways. Food and function. 2018;9(11):5950-5964.

Available:https://doi.org/10.1039/C8FO012 86E

6. Singh SK, Mukerjee A, Abhishek Tripathi HP. Nanoformulation of cinnamon oil/usnic acid blend: An attempt to improve chemopreventive effect and reduce hepatotoxicity. Journal of Medicinal Plants. 2020;8(4):311-316.

7. Vijayakumar K, Prasanna B, Rengarajan $\mathrm{RL}$, Rathinam A, Velayuthaprabhu S, Vijaya Anand A. Anti-diabetic and hypolipidemic effects of Cinnamon cassia bark extracts: An in vitro, in vivo, and in 
silico approach. Archives of Physiology and Biochemistry. 2020;25:1-1.

Available:https://doi.org/10.1080/13813455 .2020 .1822415

8. Sadeghi S, Davoodvandi A, Pourhanifeh $\mathrm{MH}$, Sharifi $\mathrm{N}$, Aref Nezhad R, Sahebnasagh $R$, Moghadam SA, Sahebkar A, Mirzaei H. Anti-cancer effects of cinnamon: Insights into its apoptosis effects. European Journal of Medicinal Chemistry. 2019;178:131-140.

Available:https://doi.org/10.1016/j.ejmech.2 019.05.067

9. Bhatt N. Cinnamon as a cancer therapeutic agent. In bioactive components, diet and medical treatment in cancer prevention. Springer, Cham. 2018;63-73.

Available:https://doi.org/10.1007/978-3319-75693-6 4

10. Hänsel R, Keller K, Rimpler H, Schneider G. Cinnamomi cortex. In: Hagers handbuch der Pharmazeutischen Praxis. Berlin. Springer Verlag. 1992;1:87-89.

11. INSA. Guidelines for care and use of animals in scientific research. Indian National Science Academy, New Delhi, India; 2000.

12. Dacie JV, Lewis SM. Practical hematology. $10^{\text {th }}$ Edn. Lewis, bain and bates, churchill livingstones. An Imprint of Elsevier. 2006;25-57.

13. Reitman S, Frankel S. A colorimetric method for the determination of serum glutamate oxaloacetic and glutamic pyruvic aminotransferases. American Journal of Clinical Pathology. 1957;28:56-63.

Available:https://doi.org/10.1093/ajcp/28.1. 56

14. Kind PR, King EJ. Estimation of plasma phosphatase by determination of hydrolysed phenol with amino-antipyrine. Journal of Clinical Pathology. 1954;7(4):322-326.

Available:https://doi.org/10.1136/jcp.7.4.32 2

15. Natelson S, Scott MI, Beffa CA. Rapid method for the estimation of urea in biological fluids. American Journal of Clinical Pathology. 1951;21(3):275-281. Available:https://doi.org/10.1136/jcp.7.4.32 2

16. Fabing DL, Ertingshausen G. Automated reaction-rate method for determination of creatinine with the centrifichem. Journal of Clinical Chemistry. 1971;17:696-700. Available:https://doi.org/10.1093/clinchem/ 17.8.696
17. Hassan SW, Ladan MJ, Dogondaji RA, Umar RA, Bilbis LS, Hassan LG, Ebbo AA, Matazu IK. Phytochemical and toxicological studies of aqueous leaves extract of Erythrophleum africanum. Pakistan Journal of Biological Sciences. 2007;10(21):3815-3821.

Available:https://doi.org/10.3923/pjbs.2007 .3815.3821

18. Wickenberg J, Lindstedt S, Nilsson J, Hlebowicz J. Cassia cinnamon does not change the insulin sensitivity or the liver enzymes in subjects with impaired glucose tolerance. Nutr J. 2014;13(1):1-6.

Available:https://doi.org/10.1186/14752891-13-96

19. Khan R, Khurshid A, Zakkia K, Safdar $\mathrm{H}$, Nawab Z, Mohammad S. Cinnamon on the functions of liver and kidney in type 2 diabetic individuals. Ann Pak Inst Med Sci. 2012;8(2):145-149.

20. Koochaksaraie RR, Irani M, Gharavysi S. The effects of cinnamon powder feeding on some blood metabolites in broiler chicks. Brazilian Journal of Poultry Science. 2011;13(3):197-202.

Available:https://doi.org/10.1590/S1516635X2011000300006

21. Torabi S, Asad MR, Tabrizi A. The effect of endurance training with cinnamon supplementation on plasma concentrations of liver enzymes (ALT, AST) in women with type 2 diabetes Tehran Univ. Med. J. TUMS Publ. 2016;74(6):433-441.

22. Moselhy SS, Ali HK. Hepatoprotective effect of cinnamon extracts against carbon tetrachloride induced oxidative stress and liver injury in rats. Biological Research. 2009;42(1):93-98.

Available:https://doi.org/10.4067/S071697602009000100009

23. Ghonim A, Abdeen A, El-Shawarby R, Abdel-Aleem N, El-Shewy $E$, Abdo $M$, Abdelhiee E. Protective effect of cinnamon against cadmium-induced hepatorenal oxidative damage in rats. International Journal of Pharmacology and Toxicology. 2017;5(1):17-22.

Available:https://doi.org/10.14419/ijpt.v5i1. 7119

24. Badgu N, Merugu R. Human alkaline phosphatases in health and disease: $A$ mini review. Int $J$ Res Pharm Sc. 2013:4:371-379.

25. Alvaro D, Benedetti A, Marucci L, Delle Monache M, Monterubbianesi R, Di Cosimo et al. Function of alkaline 
phosphatase in the liver: Regulation of intrahepatic biliary epithelium secretory activities in the rats. Hepatology. 2000;32(2):174-184.

Available:https://doi.org/10.1053/jhep.2000 .9078

26. Fulden S, Saygili F. Causes of high bone alkaline phosphatase. Biotechnology and Biotechnological 2014;21(2):194-197.

Available:https://doi.org/10.1080/13102818 .2007.10817444

27. Amacher DE. A toxicologist's guide to biomarkers of hepatic response. Human and Experimental Toxicology. 2002;21(5):253-262.

Available:https://doi.org/10.1191/09603271 02ht247oa

28. El Hilaly J, Isralli ZH, Lyoussi B. Acute and chronic toxicological studies of Ajuga iva in experimental animals. J Ethnopharmacol. 2004;21:253-262.

Available:https://doi.org/10.1016/j.jep.2003 .11 .009

29. Chawla R. Serum total protein and albumin-globulin ratio. In: (Methods and Interpretations) (eds Chawla R): Jaypee brothers medical publishers, New Delhi, India. Pract. Clin. Biochem. 1999;106-118.

30. Chaudhary A, Kumar Jha A, Yadav R, Ray $K$, Islam $R$. Effect of cinnamon cassia extracts on hyperglycemia and renal function in Streptozotocin induced diabetic mice. International Journal of Chemical Studies. 2019;7(3):2652-2657.

31. Khan A, Safdar M, Khan MMA, Khattak $\mathrm{KN}$, Anderson RA. Cinnamomum improves glucose and lipids of people with type 2 diabetes. American Diabetes Association. 2003;26(12):3215-3218.

Available:https://doi.org/10.2337/diacare.2 6.12.3215

32. Anderson RA, Zhan Z, Luo R, Guo X, Guo $Q$, Zhou J, et al. Cinnamon extract lowers glucose, insulin and cholesterol in people with elevated serum glucose. Journal of Traditional and Complementary Medicine. 2016;6(4):332-336.

Available:https://doi.org/10.1016/j.jtcme.20 15.03.005

33. Yun JW, You JR, Kim YS, Kim SH, Cho $\mathrm{EY}$, Yoon $\mathrm{JH}$, et al. In vitro and in vivo safety studies of cinnamon extract (Cinnamomum cassia) on general and genetic toxicology. Regul Toxicol Pharmacol. 2018;95:115-123.

Available:https://doi.org/10.1016/.yrtph.201 8.02.017

34. Rahman S, Begum H, Rahman Z, Ara F, lqbal $M$, Yousuf $A$. Effect of cinnamon (Cinnamomum cassia) as a lipid lowering agent on hyper cholesterolemic rats. Journal of Enam Medical College. 2013;3(2):94-98.

Available:https://doi.org/10.3329/jemc.v3i2. 16132

35. Alsoodeeri FN, Alqabbani HM, Aldossari NM. Effect of cinnamon (Cinnamomum cassia) consumption on serum lipid profiles in albino rats. Journal of Lipids; 2020. Available:https://doi.org/10.1155/2020/846 9830

36. Abotsi WKM, Ainooson GK, Gysi EB, Abotsi WKM. Acute and subacute toxicity studies of the ethanolic extract of the aerial parts of Hilleria latifolia (Lam.) H. Walt. (Phytolaccaceae) in Rodents. West Afr J Pharm. 2011;22:27-35.

37. Ahmad RA, Serati-Nouri $H$, Majid FAA, Sarmidi MR, Aziz RA. Assessment of potential toxicological effects of cinnamon bark aqueous extract in rats. International Journal of Bioscience, Biochemistry and Bioinformatics. 2015;5(1):42.

Available:https://doi.org/10.17706/ijbbb.20 15.5.1.36-44

(c) 2021 Okwuosa et al.; This is an Open Access article distributed under the terms of the Creative Commons Attribution License (http://creativecommons.org/licenses/by/4.0), which permits unrestricted use, distribution, and reproduction in any medium, provided the original work is properly cited.

Peer-review history:

The peer review history for this paper can be accessed here: http://www.sdiarticle4.com/review-history/70473 